INTERNATIONAL DESIGN CONFERENCE - DESIGN 2018

https://doi.org/10.21278/idc.2018.0239

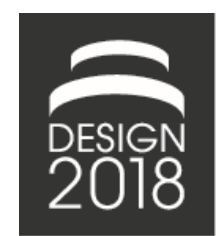

\title{
SUSTAINABILITY RISK MANAGEMENT FOR PRODUCT INNOVATION
}

\author{
J. Schulte and S. I. Hallstedt
}

\begin{abstract}
Social and environmental issues are directly connected to many of the most important risks that product development companies are facing. Based on literature review and interviews, this study investigates risk management practices on the strategic, tactical, and operational levels of companies. The findings are used to identify preconditions for integrating sustainability into risk management processes and support tools. The results show that sustainability risks need to be connected to company objectives through internal and external stakeholder value creation.
\end{abstract}

Keywords: risk management, sustainability, case study, requirements management, value

\section{Introduction}

Almost every human activity involves the use of products and services, which in turn have an impact on nature and the social system in different steps of their life cycle. Thus, solving the increasingly urgent crises in terms of the systematic degradation of ecosystem quality and the erosion of social capital, also requires a fundamental change of companies and their products and services. Several tools and mechanisms are in place to push for such a change (Bovea and Pérez-Belis, 2012), including environmental management systems (e.g. ISO 14001), sustainability indicators (Joung et al., 2013), sustainability labelling, and legislation on e.g. extended producer responsibility, etc. (Hallstedt et al., 2013). From a company perspective, the driving forces for increasing capabilities for sustainable product development are framed in terms of long-term competitiveness, through increased value creation and being ahead of legislation, while avoiding negative consequences (Bansal and Roth, 2000; Dangelico and Pujari, 2010). This means that it is a matter of smart risk management. In fact, a previous study showed that 8 out of the top 10 most important business risks are directly related to social and ecological issues (Schulte and Hallstedt, 2017a). This includes for example brand and reputation, legislative change, meeting customer needs, third party liability, and attracting top talent. A recent report by the World Economic Forum also emphasized the interconnectedness of social and ecological risks with other types of risks, such as economic ones (WEF, 2017). Sustainability risks can be defined as organizational risks that are due to social or ecological issues (Anderson, 2005). However, little is known both about the mechanisms through which sustainability risks can affect product development companies and about how a strategic sustainability perspective can be integrated into existing risk management processes and tools in practice. Therefore, the purpose of this study is (i) to increase the conceptual understanding of what sustainability risks are and how they can affect companies; (ii) to investigate how companies currently work with risk management; and (iii) to identify preconditions for sustainability integration. Literature review and interviews at case companies are combined to address the following research questions: 
RQ1: What are the current risk management practices at product development and manufacturing companies?

RQ2: What are the preconditions and success factors for sustainability integration in risk management processes and related support tools?

\subsection{Outline}

After providing a short background on risk management in a product development context, Section 2 describes the method that was applied to obtain answers to the research questions. In Section 3, the findings are presented and discussed. This is followed by Section 4, in which conclusions in relation to the research questions are drawn. The paper finishes by pointing out future research directions and topics.

\subsection{Risk management in product development companies}

Nothing about the future is for sure. Everything is uncertain and predictions are only possible based on an assessment of the likelihood of future events. Risk is however not the same as uncertainty. It is a subset of uncertainty, namely "the effect of uncertainty on objectives" (ISO, 2009). In product development companies, the importance of risk management for proactive decision-making and design improvement, including e.g. increased robustness, is today widely acknowledged and many support tools exist (Oehmen et al., 2006). Several empirical studies have shown the positive effect of risk management on product development success (Raz et al., 2002; Mu et al., 2009; Oehmen et al., 2014). Some of the main benefits with increased capabilities for risk management include (i) increased likelihood of achieving objectives; (ii) compliance with relevant legal and regulatory requirements and international norms; (iii) stakeholder confidence and trust; (iv) controls; (v) resource allocation; (vi) operational effectiveness and efficiency; (vii) loss prevention; (viii) organizational learning; and (ix) organizational resilience (ISO, 2009). There are goals and requirements that are subject to uncertainty on all levels of a company, here referred to as the strategic, tactical, and operational levels, which means that there also is risk on all levels. For that reason, sub-disciplines to risk management have evolved, e.g. enterprise risk management on the strategic level, portfolio risk management on the tactical level, and product- and process risk management on the operational level. One goal of the ISO 31000 standard is to establish communication between the functional silos in risk management and integration along different levels of decision making in the organizational hierarchy. This means that risk management processes in product development should be integrated with risk management on other levels, e.g. portfolio- and enterprise risk management. So far, limited attention has been paid to how such an integration would look like conceptually and how it could be accomplished in practice (Oehmen et al., 2010). The investigations in this study are therefore specifically considering this aspect.

\section{Method}

An interview study was conducted to map current risk management practices at product development companies and to identify preconditions for sustainability integration. This was complemented with literature review to be able to relate the findings to existing theory and state of the art. An exploratory and a descriptive approach were combined in an iterative way, as shown in Figure 1.

\subsection{Literature review}

As the first step, an exploratory literature review was conducted to identify relevant areas and themes and to get an overview of the most central theories, tools, and concepts addressing environmental or social aspects in risk management. Also, it was used to develop hypotheses and propositions to be further investigated in the following steps (Yin, 1994). The results were used to develop the interview protocol for exploratory interviews, explained in detail in the next section. Based on the findings from the exploratory literature review and the interviews, a structured literature review was conducted (Karlsson, 2009). The search focused on the areas of risk management, sustainability, and product development. Guidance by Blessing and Chakrabarti (2009) was used for the selection of the articles. 
Dependent on relevance, the selection process included the following steps: reading (i) the abstract; (ii) introduction and conclusions; (iii) results; and (iv) background, objectives, and setup. A recordand a worksheet were created to ease the structuring and analysis of the articles (Karlsson, 2009). In total, 35 articles were read in full text, whereof the most relevant ones are reviewed in Section 3.1.

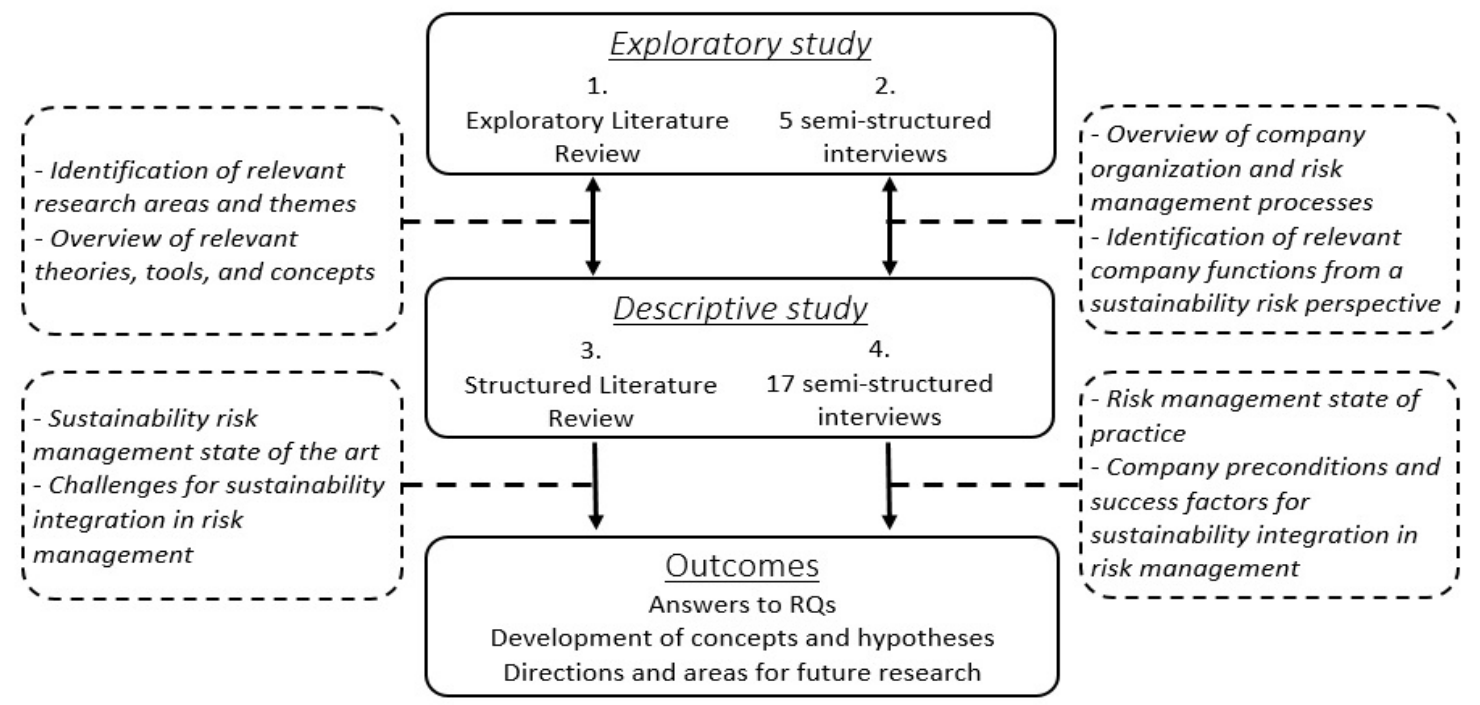

Figure 1. Overview of the research method and main outcomes of each step

\subsection{Interview study}

An interview study was performed at two large multinational product development and manufacturing companies in Sweden. Company A is a manufacturer of jet engine components in the aerospace industry with about 2000 employees. Company B is a construction machine manufacturer with about 4000 employees. Purposeful sampling was applied and the companies were selected because they have started to work with sustainability initiatives beyond the level of mere compliance, while at the same time not being companies that solely define themselves in sustainability terms. This makes them both relevant for studying how product development companies work with risk management and sustainability, and representative for a broad spectrum of businesses, allowing for more valid generalization of the results. This selection approach was previously applied by Dangelico and Pujari (2010) and Høgevold et al. (2014). In a first step, 5 one hour exploratory semi-structured interviews (Fontana and Frey, 1994) were conducted with the persons responsible for risk management processes on strategic enterprise level and operational product development level. The interviewees were identified with the help of a principle informant (Karlsson, 2009). These interviews had the main purpose to get an overview of current risk management practices and their maturity level at the companies. Due to the exploratory nature of this step, the interviews were characterized by mostly broad and open questions.

Based on the gained overview, a second, descriptive study was planned and additional 17 semistructured interviews were performed. In this step, a strategic and purposive sampling strategy was applied to include both persons with deep connection and knowledge about risk management and sustainability, as well as "peripheries", i.e. persons with less but still some connection to the research topic, ensuring variation in the data gathering activity (Karlsson, 2009). The aim was to include functions on both the strategic, tactical, and operational levels of the company. As a result, interviewee roles included, among others, enterprise risk managers, senior managers, product- and portfolio planners, purchasers, project managers, product developers, product risk managers, and environmental engineers. Interview questions were modified or adjusted according to the respondents' roles (Miles et al., 2014). Based on the purpose of the study, the interviews had two main parts: the first part, about 40 minutes, addressed current risk management practices in general, while the second part, about 20 minutes, was about sustainability risk management in particular. More specifically, the 
interview questions addressed the following themes: (i) theoretical background, e.g. the concept and meaning of risk, the perceived purpose of risk management, and connections between risk management on different organizational levels; (ii) pure inquiry, e.g. how risk activities are part of processes, categorizations of risk, and which, how, and when support tools for risk management are used; (iii) exploratory diagnostic inquiry, e.g. challenges, strengths, and improvement suggestions; and (iv) confrontive inquiry, e.g. whether the interviewees have thought about considering sustainability risks. Pilot testing was performed prior to the descriptive interview phase, to try out the interview approach and to identify potential problems, as recommended by Blessing and Chakrabarti (2009). Based on the feedback from the pilot study, the interview protocol and questions were clarified and improved. All interviews, each taking about 60 minutes, were recorded and transcribed. The transcripts were sent back to the interviewees for validation. At this point, interviewees had the possibility to make changes to the transcript. However, only minor changes, and clarifications were made. The transcripts were then used together with meeting notes and other documentation to create case narratives (Karlsson, 2009).

After this validation step, the data was coded, following the three-step scheme suggested by Strauss and Corbin (1990), starting with open coding, followed by axial coding, and finally selective coding. An outsider approach was applied (Patton, 1987) and one part of the codes was derived deductively (predefined), based on the research questions and key concepts, e.g. the different steps of the risk management process as described in ISO 31000 (ISO, 2009), while the other part of the codes was derived inductively (post-defined) (Miles et al., 2014). Dual coding was allowed, to enable multiple ways of structuring the data (Blessing and Chakrabarti, 2009). In total, 41 codes were applied and 694 incidents were assigned to those codes. Double coding was performed by coding parts of the transcription material twice with a time delay of two months in between, resulting in an intracoder reliability of $>90 \%$ (Blessing and Chakrabarti, 2009). The analysis of the data followed several tactics as suggested by Miles et al. (2014), such as noting patterns, clustering, making contrasts and comparisons, noting relations, and making conceptual coherence. Within-case analysis was performed to acquire a depth of understanding of each case as a stand-alone entity, before searching for cross-case patterns and generalizing the results (Eisenhardt, 1989). Concept networking was used to display the relationships between key aspects of the study. Feedback on the emerging network was received at multiple stages both from academic researchers and industry practitioners (Karlsson, 2009).

\section{Results and discussion}

This section starts by presenting the results of the literature review to provide an overview of the current state of the art in terms of existing theory and methods on sustainability risk management. Based on this, the results of the interview study are presented and related to the findings from the literature review.

\subsection{Literature review results: State of the art}

Sustainability risks result from environmental or social issues and have previously been categorized into six groups, (i) physical; (ii) regulatory; (iii) litigation; (iv) competitiveness; (v) reputational; and (vi) supply chain risks (Palousis et al., 2008). Anderson (2005) provided a detailed description of examples of how sustainability risks can affect companies. On the enterprise risk management (ERM) level, several suggestions for integrating sustainability into existing frameworks have been made (Aon, 2007; Pollard and Stephen, 2008; Faris et al., 2013; Lam and Quinn, 2014) and some new frameworks have been presented (Yilmaz and Flouris, 2010; Saardchom, 2013; Giannakis and Papadopoulos, 2016). The frameworks accommodate sustainability risks well on a conceptual level, however, little guidance exists for how to work with such risks in practice.

For product development, several approaches have been made to integrate environmental aspects into FMEA (Lindahl, 1999; Rozak et al., 2015). A case study in which ecological footprint was combined with environmental risk assessment was presented by Herva et al. (2011). Hallstedt et al. (2015) introduced the sustainability assessment and value evaluation (SAVE) method, which combines a strategic sustainability assessment with net present value analysis, based on scenarios. Gargalo et al. (2016) suggested a multi-level framework for techno-economic and environmental sustainability 
analysis through risk assessment to be used in early product development. In a recent study by Anand et al. (2016), a framework for a sustainability risk assessment of mechanical systems in the concept design phase was presented. Schulte and Hallstedt (2017a) identified key challenges for sustainability integration in risk management. Still, the sustainability risk assessment (SRA) framework by Palousis et al. $(2008,2010)$, which specifically targets product development, can be considered as the most foundational and comprehensive work in the area. According to the framework, sustainability risks affect companies through the following chain of cause and effect: the first step of SRA is to do a life cycle assessment (LCA) of a product or concept. In order to be a sustainability risk, (i) the impact needs to contribute to an unsustainable trend, e.g. increasing concentrations of fossil carbon dioxide; (ii) the government or global community needs to take action on that trend; and (iii) this action needs to have an effect on the life cycle cost (LCC) of the product. The underlying thought is that activities and materials that have an environmental impact, which is unsustainable and acknowledged by society, are more likely to increase in cost, e.g. due to regulation, taxes, etc. For example, emissions of SOx, which contribute to acidification, can be subject to a tax on SOx, resulting in increased costs of electricity, causing activities and materials in the value chain to become more expensive. This chain of reasoning is visualized through a sustainability risk tree, where likelihoods and consequences for each step are assessed and the final effect on product LCC is quantified. A sustainability-adjusted LCC is the final output of the SRA and shall be used to choose between different design alternatives or to improve an existing design, e.g. by avoiding high sustainability risk activities and materials.

\subsection{Interview study results: State of practice}

\subsubsection{The purpose of risk management}

The interviewees were clear on risk management in general not being about the creation of a risk-free enterprise. "We always have risks. A completely risk-free company would not be successful and definitely not creative and innovative." (Senior manager at Company B). Risk management is rather said to be about identifying and assessing how uncertainty could affect the achievement of objectives and, based on that, to take risk-informed decisions. On the strategic level, both companies described the purpose of ERM as having two main dimensions. First, ERM is used to ensure that the long-term strategy can be realized. There is a current state and a desired future state and a gap between them. The strategy is about making smart moves to fill the gap, however, every move involves risks. ERM is used to manage these risks. Second, ERM is used to secure the current operational capability on an overarching level. In summary, ERM is about ensuring that the company is profitable today and sustainable (here meaning long-term company survival) in the future, which is in line with the COSO definition (COSO, 2004). On the operational level, the purpose of project risk management is described as ensuring that project goals are achieved. The interviewees emphasize the difference between risk management in advanced engineering, focusing more on feature and design risks, and product development projects, being more about risks for time, cost, and quality. In product risk management, the purpose is stated in terms of ensuring that the product lives up to requirements, and in process risk management that the product can be manufactured in a way that lives up to the requirements of the technical drawing. This means that the purpose of risk management is expressed as ensuring that objectives on different organizational levels are met, which is in line with the ISO 31000 definition.

\subsubsection{The concept of risk}

All interviewees were familiar with risk thinking and perceived risk management to be a natural part of their daily work. Threats and opportunities were described as two inseparable parts of the same coin, because mitigating threats also can constitute opportunities. However, most of the work in practice is focusing on identifying, assessing, and managing things that could go wrong, i.e. threats.

A risk is always in relation to something, i.e. there has to be something that is at risk. When asked for what this something is, the interviewees give a variety of answers, such as compliance, cost, market share, profit, total cost of ownership, product requirements, safety, the company vision, etc. According to the ISO 31000 standard, risk is related to objectives and the interviewees' answers can be considered to be the relevant objectives from the different persons' perspectives. 


\subsubsection{Processes and support tools}

Formalized processes that include risk management activities exist on all levels. Especially on the operational level at Company B, the processes were perceived to be systematic and well-developed. On the other hand, regarding ERM processes, Company B is struggling with finding the right role of ERM and with integrating it with other existing processes in a value-adding way. Company A had more mature and established ERM processes. According to the interviewees, processes are mostly followed in practice, but many of them stress that there is a variation regarding the quality of performed risk management activities, mostly due to varying project leader awareness and top-down demand from managers. In product development, risk management activities are an integrated and continuous part of the stage-gate process. At the same time as detailed processes exist, several interviewees on the strategic and tactical levels point out the importance of experience and sometimes gut-feeling. Therefore, processes need to strike a balance between steering in detail to ensure that necessary activities are performed in a specific way, and leaving room for including experience in decision making.

Qualitative support tools dominate on all levels of the companies. Within ERM, risk matrix templates and different forms of brainstorming exercises are most used, sometimes guided by pre-defined risk categories. In product planning, a broader variety of tools exist. These are often not pure risk management tools, but rather diverse tools that include a risk perspective. For example, market trends are assessed with a PESTEL (Political, Economic, Social, Technology, Environment, Legal) analysis. Other tools that include a risk perspective are customer buying criteria and business model canvas. Further, risk is an important part in the companies' business case modelling. Today, mostly deterministic methods are used, but both companies are looking into possibilities to include some probabilistic methods, e.g. Monte Carlo simulation, in their risk management within product planning and similar functions. Within procurement, risk assessments are done through supplier evaluations in the form of checklists, questionnaires and site visits. In product development, risk registers and FMEA are the most central tools, but also many other traditional tools are used, such as fault tree analysis, 5 Why, and Ishikawa diagrams. Heatmaps are a common tool to visualize risks. Guiding questions are appreciated complements to most tools on all levels. In general, tools are considered to be all right at both companies and the challenge is rather to make people use the tools in meaningful ways and to make them a value-adding activity, rather than just a box that has to be ticked. Also, all tools are dependent on having clear objectives or requirements as an anchoring point for the risk management activities.

\subsubsection{Objectives and the connections between organizational levels}

The interviewees had some understanding of how risk management activities that they are involved in in their roles relate to risk management on other levels of the company. This is mostly true for the integration with risk management on levels that are close to the interviewees' own role. For example, a project manager clearly recognizes the connections between project- and product risk management. However, few people were able to explain how risk management processes are connected all the way from product- and process risk management to ERM. At both companies, interviewees explained that risks are cascaded upwards in the organizational hierarchy, if they are important and exceed a certain threshold, e.g. risk priority number. This cascading goes bottom-up to ensure that severe risks are dealt with on the right level and by the people with the corresponding responsibility and is included in the formal processes. However, there is no formal top-down flow between risk management processes on different levels. Risk is by definition about objectives. "If we work with risk management the right way, we start with targets and requirements." (Risk Manager at Company B). The interviewees were therefore asked how objectives on their organizational level are derived. Based on the answers, a concept map was created to visualize how the pathways that lead to objectives were described, Figure 2. 


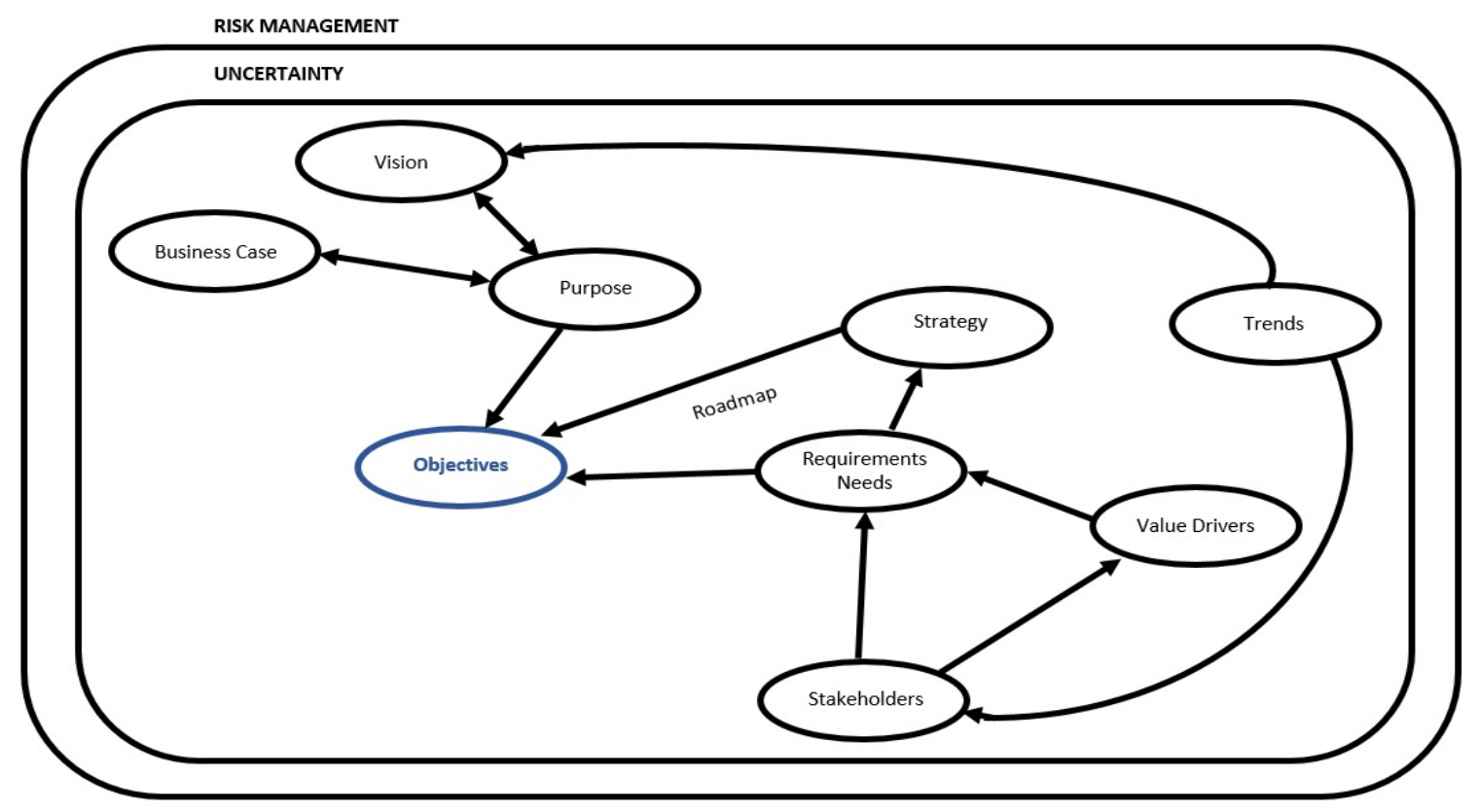

Figure 2. Concept map based on the interviewees explanations, showing the pathways for how objectives are derived

The interviewees described two pathways for how objectives are derived: first, objectives can be formulated based on the purpose and vision of the company. This can include CEO commitment for certain topics, company history, heritage, and core values. Resulting internal targets and requirements often do not need further justification, e.g. through contributing to a business case, because they are a natural part of how the company defines itself. Second, objectives can be based on stakeholder value creation. Companies aim to create value, at the same time, they exist within a societal system. Hence, requirements and needs are present at a variety of internal and external stakeholders, for example customers, suppliers, employees, and regulators. These stakeholders can have direct requirements, e.g. regulators, or they can have needs and requirements in relation to value drivers. The interviewees stressed that it is about both external and internal stakeholder value creation. Examples of external stakeholder value drivers, e.g. for the customer, could be product reliability, availability, image and status, efficiency, maintenance cost, etc., and can also include sustainability aspects (Bertoni et al., 2015). For internal stakeholders, it could be lower cost, higher employee motivation, etc. This type of objectives has to directly contribute to company competitiveness, either in the short term through improving the business case by reducing cost or better meeting customer needs, or in the long term through strategic fit. The foundation for effective risk management is therefore to have a good understanding of how to translate the company vision and stakeholder value drivers into objectives. "We never get better than our requirements. If requirements for some aspect are missing, it won't be addressed." (Risk manager at Company B). The interviewees point out that objectives usually, with some exceptions, come top-down, i.e. they start with the company vision, strategy, and an analysis of stakeholder needs, and are then broken down all the way into targets for specific projects and requirements for products and components. This means that objectives are the key for top-down communication and the translation of strategic commitment into practice, while risks are cascaded bottom-up to ensure that objectives are met, Figure 3. However, this does not imply that all risks have their source on the operational level, but rather that the direction they are cascaded usually is upwards and not downwards in the organisational hierarchy. 

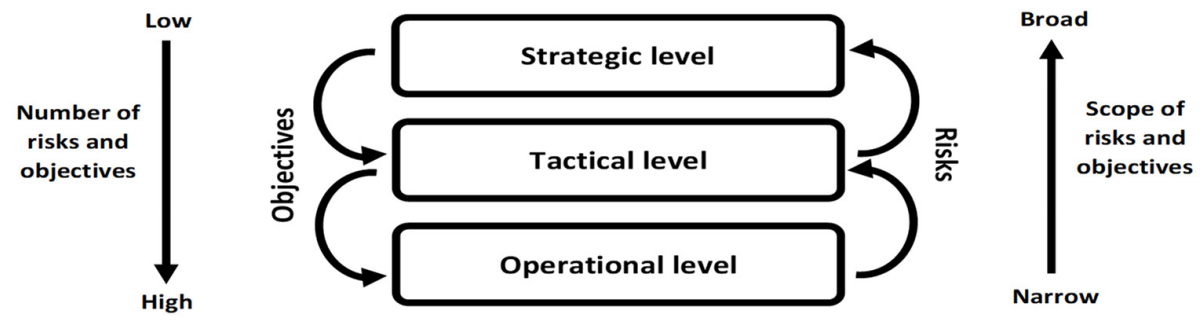

Figure 3. Schematic view, based on interviewee answers, of how objectives and risks flow to connect organizational levels

\subsubsection{Challenges and success factors}

In general, competence and awareness for risk management are pointed out as key factors for successful risk management. Selective hiring, introduction of new employees, training, and setting clear targets are mentioned as important ways to create competence and awareness and, over time, to create a risk-aware culture. The other challenges are to a large degree results of a lack of competence and awareness. This includes that managers need to request high quality risk activities and deliverables, which also is connected to the prioritization of risk management. "Risks are far away in time; we have problems now." (Product planner at Company A). The interviewees also consider it to be important to de-dramatize risk management and to make it more tangible. In some cases, risk management is also perceived as administrative and bureaucratic, making it time consuming while not value-adding. A leaner way was therefore desired by some interviewees. Several persons also stated that the companies are good at risk identification and assessment, but worse at actually mitigating risks. Clearer guidelines for which risks that need to be mitigated, i.e. a defined risk appetite, as well as dedicated persons to follow up on risks are asked for. For ERM, Company B is struggling with integrating ERM with other high-level processes. Another challenge is related to the identification of risks, especially black swan risks, and guiding questions for every risk category was mentioned as an improvement suggestion. At both companies, people point out that ERM, and strategy in general, has become more difficult over time, due to general societal changes, e.g. the amount of information and data, technology shifts, etc. This makes longerterm planning and risk management difficult, as likelihood and consequences of events cannot be predicted with any reasonable precision, so called deep uncertainty (Aven, 2016).

Procurement staff is struggling with the global nature of their organizations, which makes it difficult to standardize processes, supplier requirements, etc. The interviewees at Company A state that risk management often is done in the head of people, but not well documented, which creates an obstacle for communication and knowledge sharing. They also ask for easier support tools and templates to lower the threshold for people to start working with risk management. On the operational level, starting early and working continuously with risk management in the product development process is pointed out as a success factor. Also, a more effective way to reuse FMEA is asked for, because too much time is spent on obvious risks that are already dealt with. FMEA and risk registers could also work as vessels to carry experience for knowledge sharing and lessons learned. As the severity of risks comes top-down (from the whole product down to its parts), while the probability of occurrence comes bottom-up (components within the product cause a failure of the product), one interviewee also asked for improved possibilities to connect FMEAs between different product- and component levels.

\subsubsection{Sustainability integration in risk management}

When asking about the term "sustainability risks", the interviewees had only vague ideas of what that could be and there is no such risk category at neither of the companies. Still, after getting deeper into the discussion, it became apparent that several social and environmental risks already are considered, however not under the term "sustainability risks", e.g. environmental legislation, the ability to attract top talent, and effects on brand and reputation. This means that the interviewees are familiar with social and environmental issues affecting the company, but there is no systematic work to identify, assess, and manage sustainability risks. Neither is there an understanding of the mechanisms through which 
sustainability risks can affect different levels of the company. According to many interviewees, a necessary prerequisite for being able to understand and work systematically with sustainability risks, is to first create a shared understanding of what sustainability in general is and to have a plan for how the company wants to work with it. The importance of sustainability capabilities for company success is very much acknowledged, as also shown in a previous study (Schulte and Hallstedt, 2017b), but several interviewees perceive that it is used as a buzz-word and that the actual content is unclear and intangible.

\subsubsection{How sustainability risks affect product development companies}

Another key challenge is to see how sustainability risks are relevant and can affect the companies, i.e. to clarify the company benefits and driving forces for investing in sustainability risk management. A manager at one of the companies said: "We are so occupied with struggling to live up to the requirements specification that it is hard to think about mining in the Amazon area at the same time.". Based on the findings presented in 3.2.4, two things are needed to achieve this. First, the companies need to assess how their objectives based on purpose and vision can be affected by sustainability issues. Second, the companies need to assess how their objectives based on internal and external stakeholder value can be affected by sustainability issues. The important thing is that the effect of sustainability risks is not limited to distinct sustainability objectives. Instead, it needs to be investigated if and how sustainability aspects can affect each objective. For example, in relation to customer value drivers e.g. product performance, durability, reliability, cost of ownership and operation, resale value, etc. When these relationships between objectives, value drivers, and sustainability issues are established, the next challenge is how to assess and manage sustainability risks. The interviewees point out the complexity of sustainability issues, making them difficult to assess, quantify, and communicate. They also require a system- and life cycle perspective to avoid sub optimisation. At the same time, several interviewees stress the importance of considering sustainability risks early in product development, before concepts are chosen and too many parameters are fixed. LCA was used in one of the projects at Company B, but found to be problematic, because LCA requires detailed data, which is available first in the late stages of product development. However, at that point, it is often too late to use the results of the assessment for decision making. As a first step, suggestions from the interviewees include (i) introducing a rough and easy way to identify sustainability risks, e.g. through guiding questions or the introduction of additional risk categories, to raise the awareness; (ii) performing a simplified LCA in the concept selection phase and map how sustainability hot spots can affect stakeholder value; (iii) having a function at the company that can train and support groups who are working with sustainability risk management; (iv) mapping how objectives in general and customer value drivers in specific can be affected by sustainability risks.

\section{Conclusions}

This study has investigated the current risk management practices at different organizational levels at product development and manufacturing companies. These findings were analysed to identify preconditions for integrating a sustainability perspective in risk management processes and related decision support tools. The results were related to existing theory and research in the area to also increase the conceptual understanding of the mechanisms through which sustainability risks affect companies.

\subsection{RQ1: Risk management practices at product development companies}

The interviewees at both companies were familiar with risk thinking and most of them considered risk management to be an important part of their work. Overall, risk management is well integrated into existing processes, such as product development, purchasing, etc. and existing support tools are mostly considered to be all right. However, challenges do exist in achieving high quality risk activities and deliverables and in making risk management a value-adding practice. Insufficient request from some managers and a lack of competence and awareness are pointed out as main reasons. The understanding of how risk management on different levels of the organizational hierarchy is connected, was found to be limited. Based on an analysis of all interview results and existing research on that topic, a concept map was derived. The answers revealed that risks almost entirely are cascaded upwards in the hierarchy. The corresponding top-down flow consists of objectives, which primarily are cascaded downwards from 
the company vision and strategy, over portfolios, projects, into product requirements. Two main pathways through which objectives are derived were described by the interviewees: first, internal objectives based on company core values, and second, objectives based on creating internal and external stakeholder value. Risk management is then applied to ensure that the objectives on each level are achieved. Setting the right objectives is therefore decisive for effective risk management.

Building competence and awareness is pointed out as a key success factor and the importance of experience for decision making is stressed by many interviewees. At the same time, no mechanisms for knowledge sharing and no systematic approach to lessons learned seemed to be in place, which is an important area for improvement. Other main challenges include (i) too much focus on obvious risks and risk identification and assessment, while too little on mitigation; (ii) working early and continuously with risk management in product development; (iii) making risk more tangible and relevant, which would lead to higher prioritization.

\subsection{RQ2: Preconditions for sustainability integration in risk management}

Both in the literature and among the interviewees, there is very little understanding of what sustainability risks are and why they are important for product development companies. Existing literature on sustainability risk management has focused on the potential effects of environmental and social impact on the life cycle cost of a product (Palousis et al., 2010). Based on the findings from the interview study, this view appears to be too narrow, only covering a small fraction of the pathways through which sustainability risks can affect product development companies. Instead, this study argues that sustainability risks need to be considered in relation to company objectives on the different organisational levels. For product development, this means that the potential effect of sustainability risks has to be managed not only in relation to cost, but in relation to all stakeholder value drivers. Thereby, this paper proposes a shift from cost focus to value focus as the anchoring point for sustainability risk management, which is a considerable change.

In conclusion, this study identified three consecutive challenges for including a strategic sustainability perspective in risk management at product development companies: (i) a basic understanding of what sustainability in general and sustainability risks in specific are, needs to be established; (ii) the driving forces for working with sustainability risk management need to be clarified by identifying how sustainability aspects can affect objectives in general and internal and external stakeholder value drivers in particular. Including a sustainability perspective in objective formulation and requirement setting is of key importance for establishing a red thread throughout the organizational hierarchy. (iii) Practical ways of how to identify, assess, and manage sustainability risks need to be developed. Such processes and tools need to balance the difficulty of assessing the likelihoods and consequences of many sustainability risks with companies' needs for quantitative metrics. The main contribution of this study is, therefore, threefold: first, it provides an in-depth insight into current risk management practices at product development companies; second, it identifies company preconditions for sustainability integration is risk management; and third, it contributes to the existing theory by expanding the view of how sustainability risks can affect companies and how it connects to objectives and stakeholder value on different levels of the organizational hierarchy.

\subsection{Limitations and future research}

This study utilized literature review in combination with semi-structured interviews at two product development and manufacturing companies in Sweden, which can limit the generalizability of the findings. Based on the purpose of the study, efforts were focused on acquiring a depth of understanding, rather than a broad overview. Also, the companies were selected to be representative for many large product development companies in primarily Europe, but also other parts of the world.

Ongoing and future research is investigating how a strategic sustainability perspective can be included in goals and requirements setting, as well as how value drivers for both internal and external stakeholders can be mapped and connected to sustainability and, in the next step, systematically assessed and managed from a risk perspective. It would also be relevant to further develop and validate the concept map and to investigate the connections between organizational levels in more detail, including their relevance for sustainable product development. 


\section{Acknowledgments}

Financial support from the Knowledge Foundation in Sweden is gratefully acknowledged. Sincere thanks to the industrial research partners.

\section{References}

Anand, A., Khan, R.A. and Wani, M.F. (2016), "Development of a sustainability risk assessment index of a mechanical system at conceptual design stage", Journal of Cleaner Production, Vol. 139, pp. 258-266. https://doi.org/10.1016/j.jclepro.2016.07.147

Anderson, D.R. (2005), Corporate Survival: The Critical Importance of Sustainability Risk Management, iUniverse, Lincoln.

Aon (2007), Sustainability - Beyond Enterprise Risk Management. [online] Available at: http://www.aon.com/about-aon/intellectual-capital/attachments/riskservices/sustainability_beyond_enterprise_risk_management.pdf

Aven, T. (2016), "Risk assessment and risk management: Review of recent advances on their foundation", European Journal of Operational Research, Vol. $253 \quad$ No. 1, pp. 1-13. https://doi.org/10.1016/j.ejor.2015.12.023

Bansal, P. and Roth, K. (2000), "Why Companies Go Green: A Model of Ecological Responsiveness", The Academy of Management Review, Vol. 43 No. 4, pp. 717-736. https://doi.org/10.2307/1556363

Bertoni, M., Hallstedt, S. and Isaksson, O. (2015), "A model-based approach for sustainability and value assessment in the aerospace value chain", Advances in Mechanical Engineering, Vol. 7 No. 6, pp. 1-19. https://doi.org/10.1177/1687814015590215

Blessing, L.T.M. and Chakrabarti, A. (2009), DRM, a Design Research Methodology, Springer, London, https://doi.org/10.1007/978-1-84882-587-1

Bovea, M.D. and Pérez-Belis, V. (2012), "A taxonomy of ecodesign tools for integrating environmental requirements into the product design process", Journal of Cleaner Production, Vol. 20 No. 1, pp. 61-71. https://doi.org/10.1016/j.jclepro.2011.07.012

COSO (2004), Enterprise Risk Management — Integrated Framework, Vol. 3, AICPA, Durham.

Dangelico, R.M. and Pujari, D. (2010), "Mainstreaming green product innovation: Why and how companies integrate environmental sustainability", Journal of Business Ethics, Vol. 95 No. 3, pp. 471-486. https://doi.org/10.1007/s10551-010-0434-0

Eisenhardt, K.M. (1989), "Building theories from case study research", Academy of Management Review, Vol. 14 No. 4, pp. 532-550. https://doi.org/10.2307/258557

Faris, C., Gilbert, B., LeBlanc, B., Ballou, B. and Heitger, D.L. (2013), Demystifying Sustainability Risk: Integrating the Triple Bottom Line into an Enterprise Risk Management Program, Committee of Sponsoring Organizations of the Treadway Commission (COSO).

Fontana, A. and Frey, J.H. (1994), "Interviewing: The Art of Science”, In: Denzin, N.K. and Lincoln, Y.S. (Eds.), Handbook of Qualitative Research, Sage Publications, Thousand Oaks, pp. 361-376.

Gargalo, C.L., Carvalho, A., Gernaey, K.V. and Sin, G. (2016), "A framework for techno-economic \& environmental sustainability analysis by risk assessment for conceptual process evaluation", Biochemical Engineering Journal, Vol. 116, pp. 146-156. https://doi.org/10.1016/j.bej.2016.06.007

Giannakis, M. and Papadopoulos, T. (2016), "Supply chain sustainability: A risk management approach", International Journal of Production Economics, Vol. 171, pp. 455-470. https://doi.org/10.1016/j.ijpe.2015.06.032

Hallstedt, S.I., Bertoni, M. and Isaksson, O. (2015), “Assessing Sustainability and Value of Manufacturing Processes: A case in the aerospace industry", Journal of Cleaner Production, Vol. 108, pp. 169-182. https://doi.org/10.1016/j.jclepro.2015.06.017

Hallstedt, S.I., Thompson, A.W. and Lindahl, P. (2013), "Key elements for implementing a strategic sustainability perspective in the product innovation process", Journal of Cleaner Production, Vol. 51, pp. 277-288. https://doi.org/10.1016/j.jclepro.2013.01.043

Herva, M., Álvarez, A. and Roca, E. (2011), "Sustainable and safe design of footwear integrating ecological footprint and risk criteria", Journal of Hazardous Materials, Vol. 192 No. 3, pp. 1876-1881. https://doi.org/10.1016/j.jhazmat.2011.07.028

Høgevold, N.M., Svensson, G., Wagner, B., Petzer, D.J., Klopper, H.B. et al. (2014), “Sustainable business models: Corporate reasons, economic effects, social boundaries, environmental actions and organizational challenges in sustainable business practices", Baltic Journal of Management, Vol. 9 No. 3, pp. 357-380. https://doi.org/10.1108/BJM-09-2013-0147

ISO (2009), ISO 31000: Principles and Guidelines, ISO. 
Joung, C.B., Carrell, J., Sarkar, P. and Feng, S.C. (2013), "Categorization of indicators for sustainable manufacturing", Ecological Indicators, Vol. 24, pp. 148-157. https://doi.org/10.1016/j.ecolind.2012.05.030

Karlsson, C. (2009), Researching Operations Management, Routledge, New York. https://doi.org/10.4324/9780203886816

Lam, J. and Quinn, F. (2014), The Role of Sustainability in Enterprise Risk Management. [online] Workiva. Available http://www.jameslam.com/images/PDF/The_role_of_sustainability_in_enterprise_risk_management.pdf

Lindahl, M. (1999), "E-FMEA - A new Promising Tool for Efficient Design for Environment", Proceedings of EcoDesign'99 / the 1st International Symposium on Environmentally Conscious Design and Inverse Manufacturing, Tokyo, Japan, February 1-3, 1999, IEEE, pp. 734-740. https://doi.org/10.1109/ECODIM.1999.747707

Miles, M.B., Huberman, M.A. and Saldana, J. (2014), Qualitative Data Analysis: A Methods Sourcebook, 3rd ed., Sage Publications, Thousand Oaks, CA.

Mu, J., Peng, G. and MacLachlan, D.L. (2009), "Effect of risk management strategy on NPD performance", Technovation, Vol. 29 No. 3, pp. 170-180. https://doi.org/10.1016/j.technovation.2008.07.006

Oehmen, J., Ben-Daya, M., Seering, W. and Al-Salamah, M. (2010), "Risk Management in Product Design: Current State, Conceptual Model and Future Research", Proceedings of ASME 2010 International Design Engineering Technical Conferences and Computers and Information in Engineering Conference, Vol. 1, Montreal, Canada, August 15-18, 2010, ASME, pp. 1033-1041. https://doi.org/10.1115/DETC2010-28539

Oehmen, J., Dick, B., Lindemann, U. and Seering, W. (2006), "Risk Management in Product Development Current Methods", Proceedings of DESIGN 2006 / the 9th International Design Conference, Dubrovnik, Croatia, May 15-18, 2006, The Design Society, pp. 1551-1558.

Oehmen, J., Olechowski, A., Kenley, C.R. and Ben-Daya, M. (2014), “Analysis of the effect of risk management practices on the performance of new product development programs", Technovation, Vol. 34 No. 8, pp. 441453. https://doi.org/10.1016/j.technovation.2013.12.005

Palousis, N., Luong, L. and Abhary, K. (2008), "An integrated LCA/LCC framework for assessing product sustainability risk", WIT Transactions on Information and Communication Technologies, Vol. 39, pp. 121128. https://doi.org/10.2495/RISK080131

Palousis, N., Luong, L. and Abhary, K. (2010), "Sustainability risk identification in product development", International Journal of Sustainable Engineering, Vol. 3 No. 2, pp. 70-80. https://doi.org/10.1080/19397031003686900

Patton, M.Q. (1987), How to Use Qualitative Methods in Evaluation, Sage Publications, London.

Pollard, D. and Stephen, D.W. (2008), Sustainability, Risk and Opportunity : A Holistic Approach. [online] Global Accounting Alliance. Available at: http://www.accountingforsustainability.org/wpcontent/uploads/2011/10/CICA-A-Holistic-Approach-Report.pdf

Raz, T., Shenhar, A.J. and Dvir, D. (2002), "Risk management, project success, and technological uncertainty", $R \& D$ Management, Vol. 32 No. 2, pp. 101-109. https://doi.org/10.1111/1467-9310.00243

Rozak, M., Spilka, M. and Kania, A. (2015), "Environmental Failure Mode and Effects Analysis (Fmea) - A New Approach to Methodology", Metalurgija, Vol. 54 No. 2, pp. 449-451.

Saardchom, N. (2013), "Enterprise Risk Management under Sustainability Platform", Journal of Business and Economics, Vol. 4 No. 1, pp. 32-41.

Schulte, J. and Hallstedt, S. (2017a), "Challenges for integrating sustainability in risk management-current state of research", Proceedings of ICED'17 / the 21st International Conference on Engineering Design, Vol. 2, Vancouver, Canada, August 21-25, 2017, The Design Society, Glasgow, pp. 327-336.

Schulte, J. and Hallstedt, S. (2017b), "Challenges and Preconditions to Build Capabilities for Sustainable Product Design”, Proceedings of ICED'17 / the 21st International Conference on Engineering Design, Vol. 1, Vancouver, Canada, August 21-25, 2017, The Design Society, Glasgow, pp. 1-10.

Strauss, S. and Corbin, J. (1990), Basics of Qualitative Research: Grounded Theory Procedures and Techniques, Sage Publications, Newbury Park, CA.

WEF (2017), The Global Risks Report 2017, 12th Edition, World Economic Forum, Geneva, Switzerland.

Yilmaz, A.K. and Flouris, T. (2010), "Managing corporate sustainability: Risk management process based perspective", African Journal of Business Management, Vol. 4 No. 2, pp. 162-171.

Yin, R.K. (1994), Case Study Research, Sage Publications, London.

Jesko Schulte, M.Sc.

Blekinge Institute of Technology, Department of Strategic Sustainable Development

Stora Hammar 138, 37042 Torhamn, Sweden

Email: jesko.schulte@bth.se 